\title{
ANALISIS ZAT PEWARNA RHODAMIN B PADA SAUS CABAI YANG BEREDAR DI KAMPUS UNIVERSITAS ISLAM NEGERI RADEN FATAH PALEMBANG
}

\author{
Abdurrahmansyah ${ }^{1}$, Fitratul Aini $^{2}$, Debby Chrislia ${ }^{3 *}$, \\ ${ }^{1}$ Dosen Fakultas Tarbiyah dan Keguruan UIN Raden Fatah Palembang. \\ ${ }^{2}$ Dosen Pendidikan Biologi, Fakultas Tarbiyah dan Keguruan UIN Raden Fatah Palembang. \\ ${ }^{3}$ Mahasiswa Pendidikan Biologi, Fakultas Tarbiyah dan Keguruan UIN Raden Fatah Palembang.
}

*E-mail: debbychrislia@gmail.com

\begin{abstract}
Chili sauce is one of the most popular food product because it was used as food complement. Generally in processing manufacture chili sauce added coloring substance, so product colour interesting. Nowadays more and more food manufacturers use dye that have been banned use. Rhodamine B dye in the form of a crystalline powder green or reddish purple, odorless and dissolves easily in bright red solution berfluoresan as textile dyes. Rhodamin $\mathrm{b}$ is still no food products were found to countain rhodamine B dye such as crackers, sauces, ice and other pastries. Rhodamin B is a synthetic dye that was banned for use in foods and is certified as a hazardous material according to Minister of Healthy of Indonesian Republic No. 722/Menkes/Per/IX/1998. Rhodamin B is carcinogenic, in the long term use can cause liver damage, kidney inflammation, and cancer. The kind of research this used a quantitative approach with the experimental methods laboratory. The purpose of this study was to determine whether there rhodamin B in the test samples using thin layer chromatography (TLC). The result shows that 7 examined samples doesn't contain rhodamin B and and shows $\mathrm{f}$ count smaller than $\mathrm{f}$ table ( $\mathrm{F}$ count $<\mathrm{F}$ table) $(3,61<3,71)$. Synthetic dyes are contained in most of the analyzed samples are dyes that allow its use for food by the Regulation of the Minister of Health of Indonesia such as ponceau 4R and amarant and Contribution of research given by researchers of worksheets students and implementation plan learning.
\end{abstract}

Keywords: Chili sauce; rhodamin B; Chromatography.

\section{PENDAHULUAN}

Makanan merupakan salah satu kebutuhan pokok yang sangat penting dalam kehidupan manusia, karena seluruh masyarakat tanpa terkecuali merupakan konsumen pangan. Makanan yang dikemas biasanya mengandung bahan tambahan, yaitu suatu bahan- bahan yang ditambahkan kedalam makanan selama produksi, pengolahan, pengemasan atau penyimpanan untuk tujuan tertentu (Winarno dan Titi, 1994). Secara umum jenis makanan yang disukai khususnya makanan yang memenuhi selera dan terlihat menarik, yaitu dalam hal rupa, warna, bau, rasa, suhu dan tekstur. Agar makanan tampak lebih menarik, citarasa yang baik dan tahan lama biasanya diberi zat tambahan makanan. Islam sebagai agama yang lengkap dan sempurna juga mengatur berbagai makanan yang yang layak dikonsumsi. Oleh karena itu, dalam mengkonsumsi makanan tidak semata ditinjau dari kehalalan tetapi juga kualitas makanan tersebut. Banyak makanan halal tetapi tidak berkualitas atau tidak bergizi. Halal dan bergizi menjadi syarat kelayakan suatu makanan untuk dikonsumsi sesuai dalam Al Quran surat Al Maidah ayat 88:

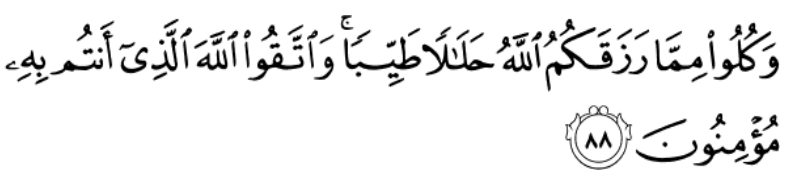

"Dan makanlah makanan yang halal lagi baik (bergizi) dari apa yang telah Allah rezekikan kepadamu, dan bertaqwalah kepada Allah yang kamu beriman kepada-Nya”. (QS. Al-Maidah:88).

Makanan jajanan seperti sosis, cilok dan siomay biasanya dilengkapi dengan saus untuk lebih menarik perhatian pembeli. Saus dalam istilah masak-memasak berarti cairan yang digunakan sewaktu memasak atau dihidangkan bersama-sama makanan sebagai penyedap atau agar makanan kelihatan bagus dan lezat. Salah satu saus yang sering ditambahkan dalam makanan adalah saus cabai. Banyak pedagang makanan jajanan di pasar atau di jalan tidak tahu dan tidak menyadari bahaya adanya bahan tambahan pangan (BTP) ilegal pada bahan baku jajanan yang mereka jual. BTP ilegal menjadi primadona bahan tambahan dijajanan kaki lima karena harganya murah, dapat memberikan penampilan makanan yang menarik (misalnya 
warnanya sangat cerah sehingga menarik perhatian pembeli) dan mudah didapat.

Penambahan pewarna pada makanan bertujuan untuk memperbaiki warna makanan yang berubah atau menjadi pucat selama proses pengolahan atau memberi warna pada makanan yang tidak berwarna agar kelihatan lebih menarik (Winarno, 1994). Akan tetapi, sering kali terjadi penyalahgunaan pemakaian zat warna pada makanan, misalnya untuk tekstil dan kulit dipakai untuk mewarnai bahan makanan (Cahyadi, 2008).

Pemerintah Indonesia melalui Peraturan Menteri Kesehatan (Permenkes) No. 239/Menkes/Per/V/1985 menetapkan 30 zat pewarna berbahaya. Rhodamin B termasuk salah satu zat pewarna berbahaya dan dilarang digunakan pada produk pangan. Namun demikian, penyalahgunaan rhodamin B sebagai zat pewarna pada makanan masih sering terjadi di lapangan dan diberitakan di beberapa media massa. Saya tertarik mengambil tema ini sebagai penelitian berdasarkan dari maraknya pemberitaan dimedia yang mengungkap bahwa adanya bahan tambahan pangan yang berbahaya bagi tubuh tapi tidak semua penjual dan pembeli makanan tersebut menyadari akan efek makanan tersebut bagi kesehatan. Melalui pengamatan di beberapa kantin di kampus UIN Raden Fatah Palembang saya menemukan bahwa adanya perbedaan warna pada saus cabai di kantin tersebut. Untuk itu kesimpulan sementara saya bahwa adanya bahan pewarna tambahan pada saus cabai di beberapa kantin UIN Raden Fatah, hanya saja karena belum diadakan penelitian lebih lanjut saya belum mengetahui apakah bahan pewarna tersebut berbahaya atau tidak bagi tubuh.

\section{METODOLOGI PENELITIAN}

\section{a. Waktu dan Tempat}

Penelitian ini dilaksanakan pada tanggal 16 sampai 22 September 2015 sedangkan tempat pengambilan sampel dilakukan di sekitar kantin kampus Universitas Islam Negeri Raden Fatah Palembang dan akan diteliti di laboratorium Poltekkes.

\section{b. Alat dan Bahan}

Alat yang digunakan dalam penelitian ini terdiri dari timbangan, gelas beker, rak dan tabung reaksi, erlenmeyer, shaker rotator, waterbath, hairdryer, spatula, labu ukur, bejana kromatografi (chamber), tisu, gelas wol, kertas whatman 1, corong gelas, mistar, plate tetes, clinipette dan yellow tip.

Bahan yang dibutuhkan dalam penelitian ini diantaranya saus cabai yang dibeli dari 7 pedagang, larutan asam asetat $\left(\mathrm{CH}_{3} \mathrm{COOH}\right) 10 \%$, aquadest, larutan elusi III yaitu larutan $\mathrm{NaCl} 2 \%$ dalam alkohol 50\%, larutan standar zat warna makanan (zat warna pembanding) yaitu rhodamin $\mathrm{b}$, ponceau $4 \mathrm{R}$, erytrosin dan amaran dan kuning FCF.

\section{c. Populasi dan Sampel}

\section{Populasi}

Menurut Sugiyono (2011), menyatakan bahwa populasi adalah wilayah generalisasi yang terdiri atas obyek/subyek yang mempunyai kualitas tertentu yang ditetapkan oleh peneliti untuk dipelajari dan kemudian ditarik kesimpulannya. Populasi penelitian ini adalah pedagang jajanan makanan yang menggunakan saus cabai yang berjualan di sekitar kampus Universitas Raden Fatah Palembang yang berjumlah 15 pedagang.

2. Sampel

Sampel adalah bagian dari jumlah dan karakteristik yang dimiliki oleh populasi tersebut. Penentuan sampel pada penelitian ini menggunakan teknik purposive sampling. Adapun kriteria sampel pada penelitian ini adalah:

a) Tidak boleh menggunakan merek yang sama dan

b) Adanya perbedaan warna pada saus cabe yang digunakan pada pedagang.

d. Prosedur Penelitian Menurut SNI 01-2895-1992 (Tentang Cara Uji Pewarna Tambahan Makanan)

1. Pengambilan Sampel

Pengambilan sampel dilakukan di kantin kampus Universitas Islam Negeri (UIN) Raden Fatah. Kegiatan yang dilakukan meliputi pengambilan sampel dan pemeriksaan sampel serta pengolahan data tambahan.

\section{Analisa Kualitatif}

Identifikasi zat pewarna sintetis pada analisa kualitatif dengan menggunakan metode kromatografi kertas (Paper Chromatography)

3. Pembuatan Elusi III : $\mathrm{NaCl} 2 \%$ dalam alkohol $50 \%$

Larutan $\mathrm{NaCl} 2 \%$ dalam alkohol 50\% dibuat dengan cara melarutkan $\mathrm{NaCl}$ sebanyak 4 gram dilarutkan dalam alkohol $50 \%$.

\section{Analisa Kromatografi Kertas}

a) Mempersiapkan sampel berbagai macam saus dengan merek yang berbeda kemudian larutkan sampel dengan $100 \mathrm{ml}$ aquadest

b) Aduk sampel menggunakan alat shaker rotator dengan kekuatan 140 selama 15 menit

c) Kemudian sampel disaring dengan tiga tahap menggunakan gelas wol, tisu dan kertas whatman

d) Sampel yang sudah jernih dan terpisah dari serat kemudian dipekatkan dengan menambahkan asam asetet $10 \%$ sebanyak $1 \mathrm{ml}$ 
e) Panaskan sampel di atas penangas air sampai mendidih. Setelah sampel mendidih kemudian sampel didinginkan terlebih dahulu sebelum ditotol di kertas whatman

f) Totolkan sampel dan zat pewarna pembanding seperti rhodamin b, kuning FCF, amarant, ponceau $4 \mathrm{R}$ dan eritrosin pada titik yang sudah ditentukan pada kertas whatman dengan elusi yang cocok yaitu $\mathrm{NaCl} 2 \%$ dalam alkohol $50 \%$

g) Kemudian masukkan kertas whatman yang sudah ditotol dengan sampel dan pewarna standar ke dalam bejana kromatografi yang lebih dahulu sudah dijenuhkan dengan elusi yang cocok. Tunggu sampai sampel mencapai fase gerak menyentuh garis dan bandingkan dengan nilai Rf bercak standar (SNI 01-28951992).

\section{e. Interpensi Hasil}

Sampel dihitung harga Rf nya. Rf (Retardation Factor) yaitu jarak dari titik awal sampai akhir noda.

$$
\mathrm{RF}=\frac{\text { Tinggi maks daya rambat sampel }}{\text { Tinggi maksimum fase gerak }}
$$

Harga Rf sampel dibandingkan dengan harga Rf warna pembanding, jika diperoleh harga Rf yang sama atau mendekati zat warna adalah jenis yang sama yaitu rhodamin b, kuning FCF, eritrosin, amaran dan ponceau 4R (Cahyadi, 2009).

\section{HASIL DAN PEMBAHASAN}

\section{A. Hasil}

Tabel 1. Analisis Zat Pewarna Rhodamin B pada Saus Cabai Pada Kertas Whatman

\begin{tabular}{|c|c|c|c|c|c|}
\hline \multirow{2}{*}{ Sampel } & \multicolumn{3}{|c|}{ Pengulangan Nilai Rf (cm) } & \multirow{2}{*}{ Rata-rata Nilai Rf (cm) } & \multirow{2}{*}{ Keterangar } \\
\hline & 1 & 2 & 3 & & \\
\hline Kontrol positif & 0,61 & 0,64 & 0,65 & 0,63 & Positif \\
\hline Kontrol negatif & 0,40 & 0,41 & 0,43 & 0,41 & Negatif \\
\hline Sampel 1 & 0,46 & 0,45 & 0,39 & 0,43 & Negatif \\
\hline Sampel 2 & 0 & 0 & 0 & 0 & Negatif \\
\hline Sampel 3 & 0,41 & 0,39 & 0,40 & 0,40 & Negatif \\
\hline Sampel 4 & 0,44 & 0,41 & 0,39 & 0,41 & Negatif \\
\hline Sampel 5 & 0,44 & 0,39 & 0,42 & 0,41 & Negatif \\
\hline Sampel 6 & 0 & 0 & 0 & 0 & Negatif \\
\hline Sampel 7 & 0,39 & 0,40 & 0,40 & 0,39 & Negatif \\
\hline
\end{tabular}

Keterangan:
a. Nilai Rf (Retardation factor): Jarak dari titik awal sampai akhir noda didapatkan dengan cara tinggi maksimum daya rambat sampel/ standar dibagi tinggi maksimum fase gerak (lampiran 2).
b. Positif : Rf rhodamin $b>$ Rf sampel
c. Negatif: Rf sampel < Rf rhodamin b.

\section{Tabel 2. Pewarna Standar}

\begin{tabular}{|c|c|c|c|c|c|c|c|c|c|c|c|}
\hline \multirow{2}{*}{ Standar Warna } & \multicolumn{3}{|c|}{ Nilai Rf (cm) } & \multirow{2}{*}{$\begin{array}{l}\text { Rata- rata } \\
\text { Nilai Rf }\end{array}$} & \multicolumn{7}{|c|}{ Sampel Saus Cabai } \\
\hline & 1 & 2 & 3 & & 1 & 2 & 3 & 4 & 5 & 6 & 7 \\
\hline Amarant & 0,30 & 0,32 & 0,36 & 0,32 & - & - & - & - & - & - & + \\
\hline Erytrosin & 0,26 & 0,28 & 0,30 & 0,28 & - & - & - & - & - & - & - \\
\hline Ponceau 4R & 0,49 & 0,50 & 0,49 & 0,49 & + & - & + & + & + & - & - \\
\hline Kuning FCF & 0,57 & 0,59 & 0,61 & 0,59 & - & - & - & - & - & - & - \\
\hline
\end{tabular}

Keterangan:

Positif : Nilai Rf sampel $>$ Rf standar

Negatif : Nilai Rf sampel $<$ Rf standar.

Tabel 3. Analisis of Varians Analisis Rhodamin B pada Saus Cabai

\begin{tabular}{cccccc}
\hline $\begin{array}{c}\text { Sumber } \\
\text { Keragaman }\end{array}$ & Derajat Bebas & Jumlah Kuadrat & Kuadrat Tengah & F Hitung & F Tabel 1\% \\
\hline Rf & 8 & 1,04 & 0,13 & $3,61^{\text {tn }}$ & 3,71 \\
Galat & 18 & 0,65 & 0,036 & & \\
Total & 26 & 1,69 & & & \\
\hline
\end{tabular}

Keterangan $^{\text {tn }}:$ Tidak nyata (F hitung $\leq \mathrm{F}$ tabel)

\section{B. Pembahasan}

Dari penelitian yang dilakukan didapatkan hasil bahwa setiap sampel yang dibeli selama tiga hari dari 7 pedagang saus di sekitar kantin kampus
Universitas Islam Negeri (UIN) Raden Fatah Palembang semua sampel tidak mengandung pewarna sintetis rhodamin b. Berdasarkan tabel 5 dapat dilihat bahwa tidak ada sampel yang 
mengandung pewarna sintetis rhodamin b. Hal ini berarti sesuai dengan Peraturan Menteri Kesehatan RI nomor 722/Menkes/Per/IX/88 yang melarang penggunaan rhodamin $\mathrm{b}$ sebagai pewarna makanan dan minuman.

Mengidentifikasi keberadaan rhodamin $b$ dalam sampel saus cabai, yaitu menggunakan Kromatografi Lapis Tipis (KLT) yang merupakan salah satu teknik pemisahan senyawa dengan prinsip adsorpsi dan koefisien partisi dengan metode kromatografi kertas dan zat pelarut yang digunakan pada penelitian ini yaitu 2 gram $\mathrm{NaCl}$ dalam alkohol $50 \%$.

Uji analisis pada sampel 1, 2, 3, 4, 5, 6 dan 7 didapatkan hasil $100 \%$ saus cabai tidak mengandung rhodamin $b$ tetapi menggunakan pewarna sintetis seperti ponceau $4 \mathrm{R}$ dan amaran yang terdapat pada sampel 1, 3, 4, 5, 7. Sedangkan pada sampel 2 dan 6 tidak terdeteksi karena sampel tersebut menggunakan pewarna alami sehingga tidak terjadi peningkatan atau pergeseran warna di kertas kromatografi.

Dan setelah dilakukan Uji F maka analisis pewarna sintetis rhodamin $b$ dari semua pedagang saus cabai menunjukkan nilai $\mathrm{F}$ hitung lebih kecil dari $\mathrm{F}$ tabel ( $\mathrm{F}$ hitung $<\mathrm{F}$ tabel) pada taraf $1 \%$ yang menunjukkan perlakuan tidak nyata (pada hasil $\mathrm{F}$ hitung ditandai dengan tn) yang berarti $\mathrm{H}_{0}$ pada hipotesis diterima dan $\mathrm{H}_{1}$ ditolak dan menyatakan bahwa tidak ada saus cabai yang mengandung rhodamin B.

Pewarna alami merupakan zat warna yang berasal dari ekstrak tumbuhan (seperti bagian daun, bunga, biji), hewan dan mineral yang telah digunakan sejak dahulu sehingga sudah diakui bahwa aman jika masuk kedalam tubuh. Pewarna alami yang berasal dari tumbuhan mempunyai berbagai macam warna yang dihasilkan, hal ini dipengaruhi oleh beberapa faktor, seperti jenis tumbuhan, umur tanaman, tanah, waktu pemanenan dan faktor-faktor lainnya. Sedangkan pada sampel yang menggunakan pewarna sintetis seperti ponceau $4 \mathrm{R}$ dan amaran terlihat laju warnanya ikut bergeser bersamaan dengan elusi yang terserap pada kertas kromatografi warnanya sangat meningkat ke atas. Penggunaan zat warna sintetis semakin luas dan keunggulan zat warna sintetis antara lain lebih murah, lebih stabil, lebih tahan terhadap berbagai kondisi lingkungan, daya mewarnainya lebih kuat dan memiliki rentang warna yang lebih luas (Nollet, 2004). Selain itu tebal dan kerataan pada saat penotolan sampel juga mempengaruhi gerakan noda dalam kromatografi lapis tipis yang akan memberikan hasil Rf yang berbeda pula.
Hasil ini menunjukkan pula bahwa pewarna sintetis yang terdapat pada sebagian besar sampel yang dijual di lokasi sampling merupakan pewarna yang diizinkan penggunaannya untuk makanan dan minuman menurut Permenkes RI No. 722/Menkes/Per/IX/88 diantaranya adalah ponceau 4R dan amarant. Pewarna ponceau 4R dan amaran termasuk pewarna sintetis yang aman dan diizinkan penggunaannya tetapi memiliki batas maksimum penggunaannya $200 \mathrm{mg} / \mathrm{kg}$. Pada zat pewarna sintetis maupun alami yang digunakan dalam industri makanan harus memenuhi standar nasional dan internasional. Penyalahgunaan zat pewarna melebihi ambang batas maksimum atau penggunaan secara ilegal zat pewarna yang dilarang digunakan dapat mempengaruhi kesehatan konsumen, seperti timbulnya keracunan akut dan bahkan kematian. Pada tahap keracunan kronis, dapat terjadi gangguan fisiologis tubuh seperti kerusakan syaraf, gangguan organ tubuh dan kanker (Cahyadi, 2008).

Pengaruh yang ditimbulkan karena proses pembuatan zat warna sintetis biasanya melalui perlakuan dengan pemberian asam sulfat atau asam nitrat yang sering terkontaminasi oleh logam berat yang bersifat racun. Disamping itu, perlu diingat dalam pembuatan zat warna organik sebelum mencapai produk akhir harus melalui senyawasenyawa antara terlebih dahulu yang kadang- kadang berbahaya dan kadang tertinggal pada akhir atau mungkin dapat terbentuk senyawa- senyawa baru yang berbahaya bagi kesehatan manusia.

Produsen dan pedagang jajanan makanan secara sengaja mencampurkan beberapa warna tunggal untuk memperoleh warna yang diinginkan sehingga menghasilkan penampilan yang menarik. Meskipun merupakan pewarna yang diizinkan penggunaannya untuk makanan, namun prinsip penggunaannya tetap dalam jumlah yang tidak melebihi keperluan untuk memperoleh efek yang diinginkan (Winarno, 1991). Pemakaian bahan pewarna sintetis dalam pangan walaupun mempunyai dampak positif bagi produsen dan konsumen, diantaranya dapat membuat suatu pangan lebih menarik, meratakan warna pangan, dan mengembalikan warna dari bahan dasar yang hilang atau berubah selama pengolahan, ternyata dapat pula menimbulkan hal-hal yang tidak diinginkan dan bahkan mungkin memberi dampak negatif terhadap kesehatan manusia.

Pengggunaan pewarna sintetis oleh para pedagang makanan tradisional di pasar- pasar atau di kantin atau kios pada makanan disebabkan kurangnya pengetahuan terhadap bahaya pewarna sintetis yang dilarang. Selain itu pertimbangan harga 
relatif murah sehingga para pedagang menggunakan pewarna yang tidak diizinkan tersebut.

\section{KESIMPULAN}

Dari hasil penelitian didapatkan bahwa tidak terdapat pewarna Rhodamin b di dalam saus cabai yang beredar di kampus Universitas Negeri Islam (UIN) Raden Fatah Palembang.

\section{DAFTAR PUSTAKA}

[1] Alfatih. 2009. Terjemah Tafsir Per Kata Kode Tajwid Arab. Pustaka Alfatih: Jakarta

[2] Cahyadi, W. 2008. Analisis dan Aspek Kesehatan Bahan Tambahan Pangan. Jakarta: Bumi Aksara

[3] Depkes RI. 1988. Peraturan menteri Kesehatan Republik Indonesia Nomor 722/Menkes/Per/IX/1988 Tentang Bahan tambahan Makanan. 20 September 1988. Jakarta

[4] Hanafiah, K. Ali. 2012. Rancangan Percobaan Teori dan Aplikasi Edisi Ketiga. Palembang: Fakultas Pertanian Universitas Sriwijaya
[5] Nollet. 2004. Analisa Pewarna rhodamin (http://chapter2.pdf/) diakses Senin 26 Oktober 2015 pukul 08.00 WIB

[6] Peraturan Menteri Kesehatan RI No.239/MenKes/Per/V/85 tentang Zat Warna Tertentu yang dinyatakan sebagai Bahan Berbahaya

[7] Putra, I.R. 2014. Gambaran Zat Pewarna Merah pada Saus cabai yang Terdapat pada Jajanan yang dijual di Sekolah Dasar Negeri Kecamatan Padang Utara. Jurnal Kesehatan Andalas.2014;3113

[8] SNI (Standar Nasional Indonesia), Cara Uji Pewarna Tambahan Pangan Pusat Standarisasi Industri Departemen Perindustrian 01-2895-1992

[9] Sugiyono. 2012. Metode Penelitian Kuantitatif Kualitatif dan R\&D. Bandung: Alfabeta

[10] Winarno, F.G. dan Titi, S.R. 1994. Bahan Tambahan Untuk Makanan dan Minuman. PT Pustaka Harapan: Jakarta

[11] Winarno, F.G. 2004. Kimia Pangan dan Gizi. PT Gramedia Pustaka Utami: Jakarta 